\title{
Influence of Surface Roughness on Color Changes in Building Stones
}

\section{Benavente, ${ }^{1,2}$ F. Martínez-Verdú, ${ }^{3 *}$ A. Bernabéu, ${ }^{1,2}$ V. Viqueira, ${ }^{3}$ R. Fort, ${ }^{2,4}$ M.A. García del Cura, ${ }^{2,4}$ C. Illueca, ${ }^{3}$ S. Ordóñez ${ }^{1,2}$}

\author{
${ }^{1}$ Department of Earth and Environment Sciences, University of Alicante, Alicante, Spain \\ ${ }^{2}$ Laboratory of Applied Petrology. Associated Unit CSIC-UA, Alicante, Spain \\ ${ }^{3}$ Department of Optics, University of Alicante, Alicante, Spain \\ ${ }^{4}$ Institute of Economic Geology CSIC-UCM, Alicante, Spain
}

Received 10 February 2002; revised 30 September 2002; accepted 11 November 2002

Abstract: The influence of surface roughness on color change in several Spanish building stones is studied in samples of the following: Red Alicante, Black Marquina, White Macael, and Yellow Triana. In an experimental laboratory test (acid attack), we simulated the weathering process and made a comparative analysis between this and the polishing process. Changes in both color and roughness were measured during these processes. In limestones with medium or high chroma (Red Alicante) and both low chroma and lightness (Black Marquina), the total color changes were particularly affected in both the polishing and acid attack processes. On the other hand, in marbles with both low chroma and high lightness (White Macael and Yellow Triana), the total color changes were almost imperceptible in both processes. However, no change occurred in the hue of any of the analyzed stones. Spectrophotometric data showed that color change was due mainly to changes in surface roughness and not to chemical reactions that may have altered the oxidation state of the chromophore in the chromogen of the stone. () 2003 Wiley Periodicals, Inc. Col Res

\footnotetext{
*Correspondence to: F. Martinez-Verdú, Department of Optics, University of Alicante, Apdo 99 E-03080 Alicante, Spain (e-mail: verdu@ua.es)

Contract grant sponsor: Research Project GV-97-RN-14-3 Contract grant sponsor: predoctoral research fellowship from Generalitat Valenciana awarded to D. Benavente.

(C) 2003 Wiley Periodicals, Inc.
}

Appl, 28, 000-000, 2003; Published online in Wiley InterScience (www.interscience.wiley.com). DOI 10.1002/col.10178

Key words: spectrophotometry; architecture; aesthetics; preservation; restoration

\section{INTRODUCTION}

The color of building stones, and particularly of geologic marble and limestones, is one of the most important characteristics that define their aesthetic properties. Stone has been widely used from ancient times to the present not only in monuments but also in the decoration of buildings. Its main uses are in sculpture, cladding, and pavement, and its ornamental value depends on its mechanical properties, durability, color, and conservation of color. Because many aesthetic decays are produced by environmental conditions and urban pollution, stone color stability is an essential parameter that must be understood and monitored. ${ }^{1-5}$ The quantification of this decoloration process by aging is important for the stone industry and for architectural conservation.

Color changes in these kinds of materials are usually attributed to the oxidation degree of the chromophore in the chromogen minerals and their concentrations.5,6 For example, one of the most powerful chromophores in these kinds of materials is iron. Thus, mineral phases with oxidized ferric material produce a red-brown color in the stone, 
TABLE I. Summary of some important petrophysical and structure characteristics of the stones (approximate amount: ++++ , high; +++ , medium; ++ , low; + , scarce).

\begin{tabular}{|c|c|c|c|c|}
\hline $\begin{array}{l}\text { Petrographic } \\
\text { characteristic }\end{array}$ & $\begin{array}{c}\text { Red } \\
\text { Alicante }\end{array}$ & $\begin{array}{c}\text { Black } \\
\text { Marquina }\end{array}$ & $\begin{array}{l}\text { White } \\
\text { Macael }\end{array}$ & $\begin{array}{l}\text { Yellow } \\
\text { Triana }\end{array}$ \\
\hline $\begin{array}{l}P_{\text {connec }}(\%)(0.001-100 \mu \mathrm{m}) \\
\text { Macroporosity }(0.1-2 \mathrm{~mm})\end{array}$ & 1.3 & $\begin{array}{c}0.98 \\
+\end{array}$ & 0.05 & 1.19 \\
\hline Brecciated structure & ++ & ++ & ++ & \\
\hline Foliated structure & & & +++ & +++ \\
\hline Stylolites & +++ & ++++ & & ++ \\
\hline Veins & +++ & ++++ & & ++++ \\
\hline Fractures & ++ & ++ & ++ & ++++ \\
\hline
\end{tabular}

whereas reduced phases produce a blue-black color. When these rocks are exposed to the atmosphere, oxidation reactions occur. For this reason, reduced phases change color quickly, whereas oxidized phases remain generally stable during exposure to weathering. ${ }^{5}$

However, because gloss $^{7-10}$ and polish ${ }^{5}$ can influence color, it is reasonable to expect that color changes can also be produced by surface roughness variations. Thus, dark or high-chroma objects are particularly affected by changes in gloss, whereas high-lightness objects are not. This can be attributed to the specular component of the light that is selectively reflected. The specular component contributes less than the diffuse component to "dilution" of the colored light reflected from the object. Consequently, glossier samples, which have a nonrough surface and a larger specular component, and, therefore, less "dilution," have higher perceived chroma. ${ }^{10}$ In any case, there is no a change in the hue, because the band structures of the chromophore compounds of the stone remain constant, without any changes in the allowed and forbidden transitions in the visible band. ${ }^{11,12}$

Polishing is another process that has a significant effect on the color perceived. Basically, during the polishing process, the surface roughness of objects is decreased by grinding the surface with ever-decreasing grain-size abrasives. ${ }^{13}$ In fact, a polished surface is the most common finish used for these materials. Because there are no chemical reactions in the chromophore in the polish process, the understanding of roughness and color changes in the polishing process can be applied to the evaluation of the effects on the stone color by weathering. Therefore, the color change observed in this process can be attributed to the roughness of the stone surface.

In recent years, interest in the use of color as a visual parameter of quality control and standardization [color coding: International Commission on Illumination (CIE), Munsell, and Natural Colour System (NCS), etc.] has increased in the stone industries and related sectors. However, few studies have successfully broached the problem of measuring nongloss color in either polished samples or, more importantly, in heterogeneous samples with significantly different chromatic textures (veins, grains, stylolites). Color measurement without gloss is solved easily with the use of CIE geometry of illuminating and viewing for reflection such as $45 / 0$ or $0 / \mathrm{d}$ with gloss trap. ${ }^{7,8,14}$ On the other hand, problems arising from the heterogeneity of these natural stones may be solved by using a small measurement aperture in spectrophotometers and telespectroradiometers. Another possible solution might be the use of a digital camera in which each pixel of the captured image has been previously characterized, both spatially and colorimetrically. Thus, with the optimal magnification of the optical system, the RGB digital data can be transformed into CIE-XYZ tristimulus values.

Our aim in this article is to evaluate the influence of these natural materials on color changes relative to both variation of the chromophore and stone surface roughness by weathering. For this purpose, an experimental laboratory test (acid attack) is used to simulate the weathering process and is compared to the polishing process. A detailed study of the evolution of both color and roughness is realized during these processes to understand the important aesthetic changes in stone through weathering.

\section{MATERIALS AND METHODS}

For this study, we chose two types of geologic marble or metamorphic rock and three types of fossiliferous limestone, all of which are not only commonly used Spanish building materials but also are exported all over the world because of their different color and petrographic characteristics.

These fossiliferous limestones are classified and used as commercial marble, because they are only capable of acquiring a polished finish through mechanical processes. The studied limestones are formed by calcite crystals of varying sizes, with a predominance of calcite fossils and crystals

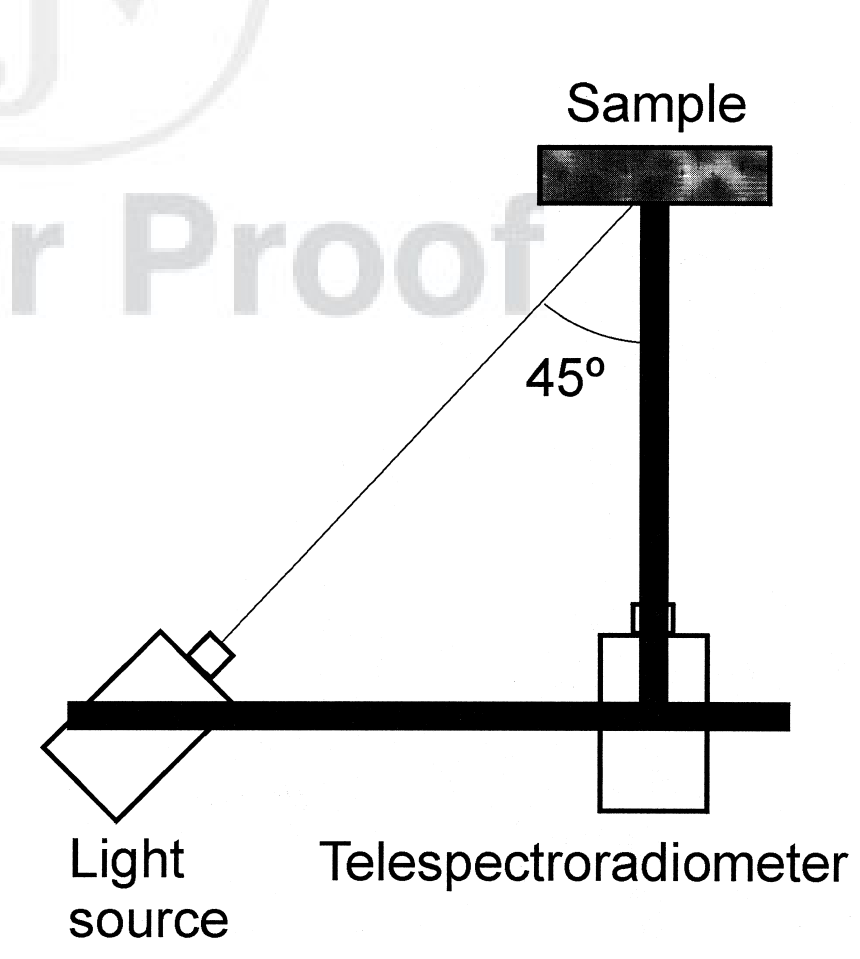

FIG. 1. CIE geometry $45 / 0$ used to obtain the spectral radiance factor $\beta$ of a stone sample. 


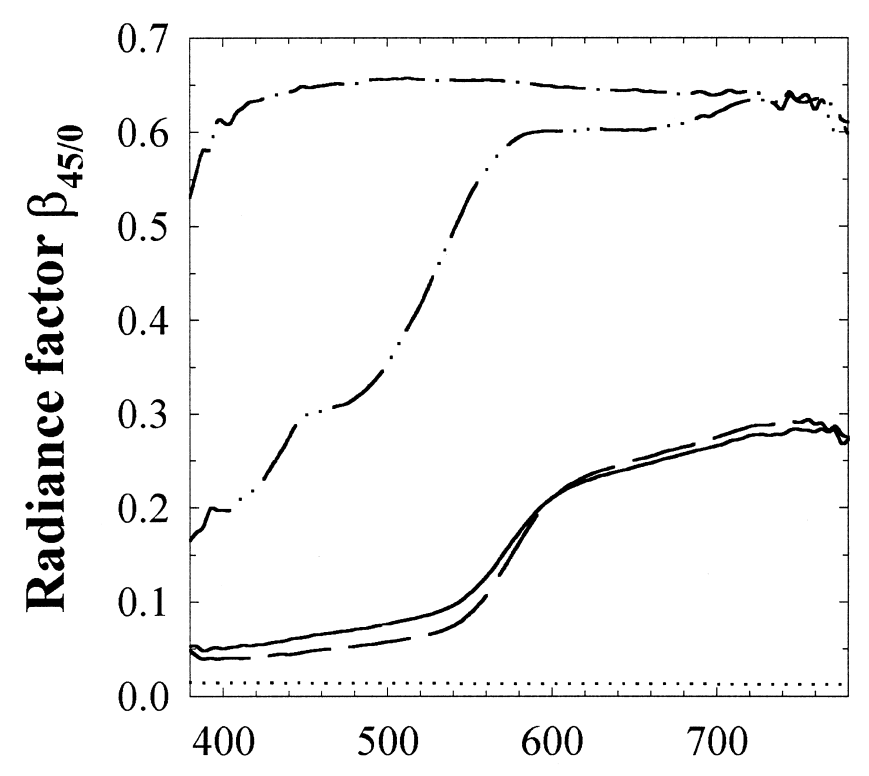

Wavelength $\lambda(\mathbf{n m})$

FIG. 2. Spectral radiance factor $\beta_{45 / 0}(\lambda)$ of some analyzed stones: Red Alicante-1 (solid line), Red Alicante-2 (dashed line), Black Marquina (dotted line, White Macael (dash-dot line), and Yellow Triana (dash-dot-dot line).

with a size $\leq 2 \mu \mathrm{m}$, which geologists call micrite. The studied metamorphic marbles are mainly formed by calcite and/or dolomite crystals that are generally visible to the naked eye.

Red Alicante is a fossiliferous limestone (Biomicrite ${ }^{15}$ ) with veins and stylolites. Fossils are mainly fragments of thin pelecypod pellet shells. Pelecypod fragments are made up of calcite crystals and measure a few millimeters in length. The size of the calcite matrix varies between 1 and $5 \mu \mathrm{m}$, because the micrite is recrystallized at some points. Red Alicante is a commercial marble, and the chromogen minerals are mainly iron oxides and iron hydroxides. In this project, the two varieties of Red Alicante we studied (Red Alicante-1 and Red Alicante-2) have some differences in their petrographic and color characteristics. ${ }^{16} \mathrm{~A}$ summary of the petrographic characteristics of Red Alicante is shown in Table I.

White Macael is a macrocrystalline calcite marble (crystals are $0.6-4.0 \mathrm{~mm}$ ) with intercrystalline porosity. Twinning calcite crystals with lamellae exfoliation are present with intra- and intercrystalline quartz, muscovite, and other silicate minerals. There are no chromogen minerals in the marble. A summary of the petrographic characteristics of White Macael is shown in Table I.

Yellow Triana is a dolomitic, mesocrystalline, heteroblastic marble. Dolomite crystal size modes range from 0.02 to $0.04 \mathrm{~mm}$, from 0.2 to $0.4 \mathrm{~mm}$, or can measure more than $8 \mathrm{~mm}$, in which case they have a rhombohedral shape. Hexagonal opaque minerals are present, and diameters of hexagonal sections range from 30 to $80 \mu \mathrm{m}$. Porosity is mainly intercrystalline. Yellow Triana is a marble, and the chromogen minerals are mainly iron oxides and iron hydroxides. A summary of the petrographic characteristics of Yellow Triana is shown in Table I.

Black Marquina is a fossiliferous limestone (Biomicrite $^{15}$ ) containing numerous veins and stylolites. Fossils have a crystal size mode ranging from 2 to $4 \mathrm{~mm}$. Fracture, channel, and circun-granular porosity are present. Intense stylolitization affects limeclasts and fossils. Small opaque minerals tend to accumulate along some stylolites, in fossils, and even coat some limeclasts. Black Marquina is a commercial marble, and the chromogen minerals are mainly organic matter. A summary of the petrographic characteristics of Black Marquina is shown in Table I.

We obtained the connected porosity using Autoscan-33 mercury porosimetry.

\section{Color and Roughness Measurements}

To measure the color of the different stone samples, the selected CIE geometry was $45 / 0^{7,8,14}$; that is, the sample was illuminated at $45^{\circ}$, and the reflected light was recollected by a telespectroradiometer at $0^{\circ}$ (Fig. 1). With this geometric configuration, the gloss of the stone is excluded. Our light source was a conventional halogen lamp, and the telespectroradiometer was a Photo Research PR-650 with an MS-75 measuring head. All the samples were $2.0 \times 2.8 \mathrm{~cm}$, and the measurement area for each was a circular spot with a 4-mm radius, small enough to select a homogeneous zone in all cases. The spectrophotometric mean values were taken from three measurements.

With this CIE geometry, we calculated the spectral radiance factor ${ }^{14}$ of each sample using the ratio of the spectral power distribution of the sample to the white reference (Halon white). From the spectral radiance factor (Fig. 2) of the most polished sample (defined below), the associated

TABLE II. CIE- $L^{*} a^{*} b^{*} C^{*} h^{*}$ parameters under D65 illuminant and approximate Munsell notation $\mathrm{H}$ V/C (hue value/chroma) under illuminant $\mathrm{C}$ of the stones.

\begin{tabular}{|c|c|c|c|c|c|}
\hline Color coding & $\begin{array}{c}\text { Red } \\
\text { Alicante-1 } \\
\end{array}$ & $\begin{array}{c}\text { Red } \\
\text { Alicante-2 } \\
\end{array}$ & $\begin{array}{c}\text { Black } \\
\text { Marquina }\end{array}$ & $\begin{array}{c}\text { White } \\
\text { Macael }\end{array}$ & $\begin{array}{l}\text { Yellow } \\
\text { Triana }\end{array}$ \\
\hline$L^{*}$ & 43.71 & 41.56 & 11.58 & 84.65 & 77.03 \\
\hline$a^{*}$ & +11.80 & +16.87 & -2.01 & -8.16 & -4.01 \\
\hline$b^{*}$ & +20.40 & +24.25 & -2.12 & -4.39 & +23.70 \\
\hline$C^{*}$ & 23.56 & 29.54 & 2.93 & 9.27 & 24.04 \\
\hline$h^{\star}(\mathrm{deg})$ & 59.95 & 55.17 & 226.53 & 208.27 & 99.61 \\
\hline $\mathrm{H}$ V/C & $5 Y R \quad 4 / 4$ & $2.5 Y R \quad 4 / 6$ & $\mathrm{~N} 1 /$ & N 8.5/ & $2 Y 7.5 / 4$ \\
\hline
\end{tabular}


TABLE III. Distribution of the grain size of the abrasives and type of abrasive used for the polishing process.

\begin{tabular}{ccl}
\hline Stage & $\begin{array}{c}\text { Grain number } \\
\text { of the abrasive }\end{array}$ & \multicolumn{1}{c}{ Type of abrasive } \\
\hline 0 & - & Sawn \\
1 & 80 & SiC-grinding paper \\
2 & 120 & SiC-grinding paper \\
3 & 1200 & Resin-bonded diamond \\
4 & $6 \mu \mathrm{m}$ & Spray diamond \\
5 & $3 \mu \mathrm{m}$ & Spray diamond \\
\hline
\end{tabular}

tristimulus values CIE-XYZ and CIE- $L * a * b * C * h *$ (Table

II) under D65 illuminant are obtained, ${ }^{7-9,14}$ as well as the approximate Munsell notation $\mathrm{H} \mathrm{V/C} \mathrm{(hue} \mathrm{value/chroma)}$ under illuminant C. ${ }^{9}$

To quantify the roughness variations, $R_{a}$ was calculated from the surface roughness tester Mitutoyo SJ-201. $R_{a}$ (in micrometers), defined as the arithmetic average profile, was obtained with a measuring line $12.5 \mathrm{~mm}$ long. The mean roughness was taken from three measurements.

\section{Polishing Process}

To study changes in color and roughness, the samples underwent exhaustive grinding and polishing, and were measured for changes after each polishing stage. The reference values for this study were sawn samples. Because color and roughness measurements are nondestructive, both parameters can be monitored throughout the polishing process. Measurements were always taken in the same place on each sample. Color measurements were always performed at one point, whereas roughness measurements were recorded at three points on the stone surface, near the color reference.

We polished the stone surfaces by grinding them with ever-decreasing grain-size abrasives. Polishing was completed with the application of a spray of monocrystalline diamonds to diminish microroughness. The stone was carefully rinsed after each polishing stage. The sequence of each sample preparation, the distribution of the grain size of the abrasives used for the polishing process, and the types of abrasive are shown in Table III. The duration of each grinding operation was $15 \mathrm{~min}$. The samples were loaded onto the abrasives at a force of $90 \mathrm{~N}$. The samples we used were $2 \times 2.8 \times 0.8 \mathrm{~cm}$ prisms, and polishing was carried out on the $2 \times 2.8 \mathrm{~cm}$ side.

\section{Acid Attack Test}

To study the mechanisms that cause decay in building materials when exposed to a polluted environment, as well as the effects produced, experiments are usually carried out in simulated conditions. There are standard tests, some of which are based on the immersion of samples into an $\mathrm{H}_{2} \mathrm{SO}_{4}$ solution; others are based on the exposure of samples to $\mathrm{SO}_{2}$ gases. In both cases, differences between them are due to temperature, humidity, and sample exposure time. ${ }^{17,18}$

In this study, we chose to immerse polished samples into an $\mathrm{H}_{2} \mathrm{SO}_{4}$ solution, because a dissolution process is mainly produced. In other words, the dissolution process causes material loss on the surface and therefore increases the surface roughness. However, in the exposure to $\mathrm{SO}_{2}$ experiment, both dissolution and mineral precipitation occurs. The minerals formed on the surface of these samples have a different color and can therefore alter the results of this research.

The acid condition generated in the $\mathrm{H}_{2} \mathrm{SO}_{4}$ solution $(\mathrm{pH}$ 3.70) simulates weathering of the building material. The temperature was kept constant $\left(25^{\circ} \mathrm{C}\right)$ throughout the experiment. The acid attack was carried out with the same samples used in the polishing experiment. Thus, this comparative study of the influence of roughness on color is more accurate. Indeed, a polished surface is the most common finish used for these materials, and the effect of this induced alteration is most comparable to real weathering. Both surface roughness and color were monitored over $0,12,24$, and $72 \mathrm{~h}$.

\section{RESULTS AND DISCUSSION}

\section{Roughness Changes}

Roughness changes, which are measured by $R_{a}$ (in micrometers), caused by both the polishing process and the acid attack are summarized in Table IV. The variation of roughness in Red Alicante-1 during both processes is shown in Fig. 3. These results demonstrate the inverse relationship between the polishing process and stone decay (weathering).

During the polishing process, stone surface roughness is decreased by grinding with increasingly smaller abrasives (stages 1,2, and 3); finally, polishing is completed with the application of a spray of monocrystalline diamonds to diminish the microroughness (stages 4 and 5). Thus, many changes occur in the surface roughness during the grinding process, whereas it is stabilized in the final stages and reaches 0 (Fig. 3). On the other hand, during the acid attack,

TABLE IV. Surface roughness variations on the stones, $R_{a}$ (micrometers), during the polishing and acid attack processes.

\begin{tabular}{|c|c|c|c|c|c|}
\hline & $\begin{array}{c}\text { Red } \\
\text { Alicante-1 }\end{array}$ & $\begin{array}{c}\text { Red } \\
\text { Alicante-2 }\end{array}$ & $\begin{array}{c}\text { Black } \\
\text { Marquina }\end{array}$ & $\begin{array}{l}\text { White } \\
\text { Macael }\end{array}$ & $\begin{array}{l}\text { Yellow } \\
\text { Triana }\end{array}$ \\
\hline Polishing & $-3.29 \pm 0.25$ & $-2.64 \pm 0.56$ & $-7.98 \pm 0.66$ & $-3.85 \pm 0.15$ & $-1.66 \pm 0.03$ \\
\hline Acid attack & $8.95 \pm 2.08$ & $0.54 \pm 0.11$ & $0.45 \pm 0.06$ & $0.20 \pm 0.06$ & $1.71 \pm 0.46$ \\
\hline
\end{tabular}



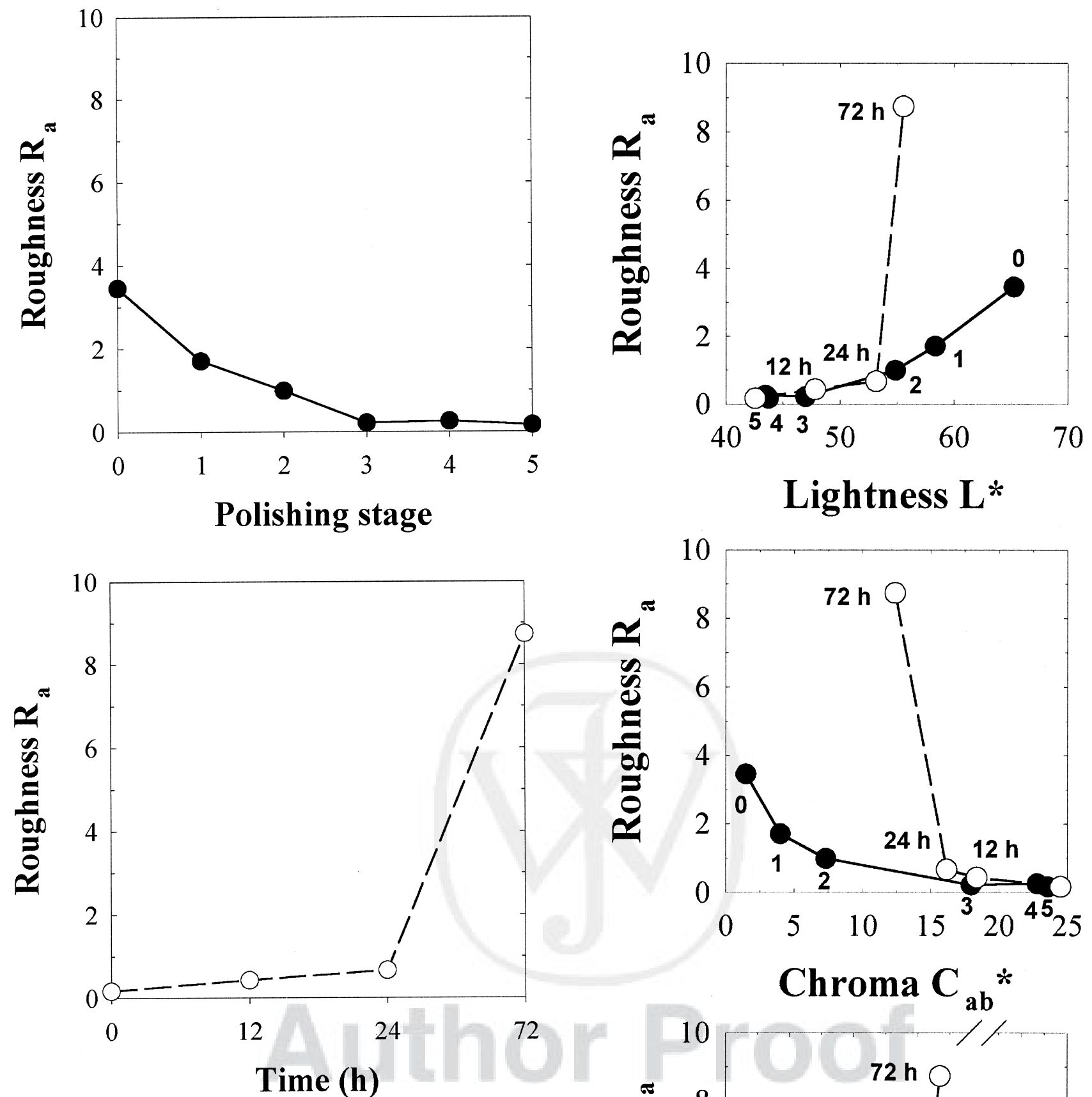

FIG. 3. Relationships between the roughness $R_{a}$ of the Red Alicante-1 with the level of the polishing (top) and the acid attack course (bottom).

the stone grains are dissolved; therefore, the stone surface roughness increases. Because the solution is undersaturated in the mineral phases, which are therefore dissolving, the dissolution process continues throughout the experiment.

FIG. 4. Relationships between the roughness $R_{a}$ of the Red Alicante-1 with its lightness $L^{*}$ (top), chroma $C^{*}$ (center), and hue angle $h^{*}$ (bottom) throughout the polishing $(\bullet)$ and the acid attack $(\mathrm{O})$ processes. Each symbol is also identified by a sublegend showing the partial characteristics of the two processes.
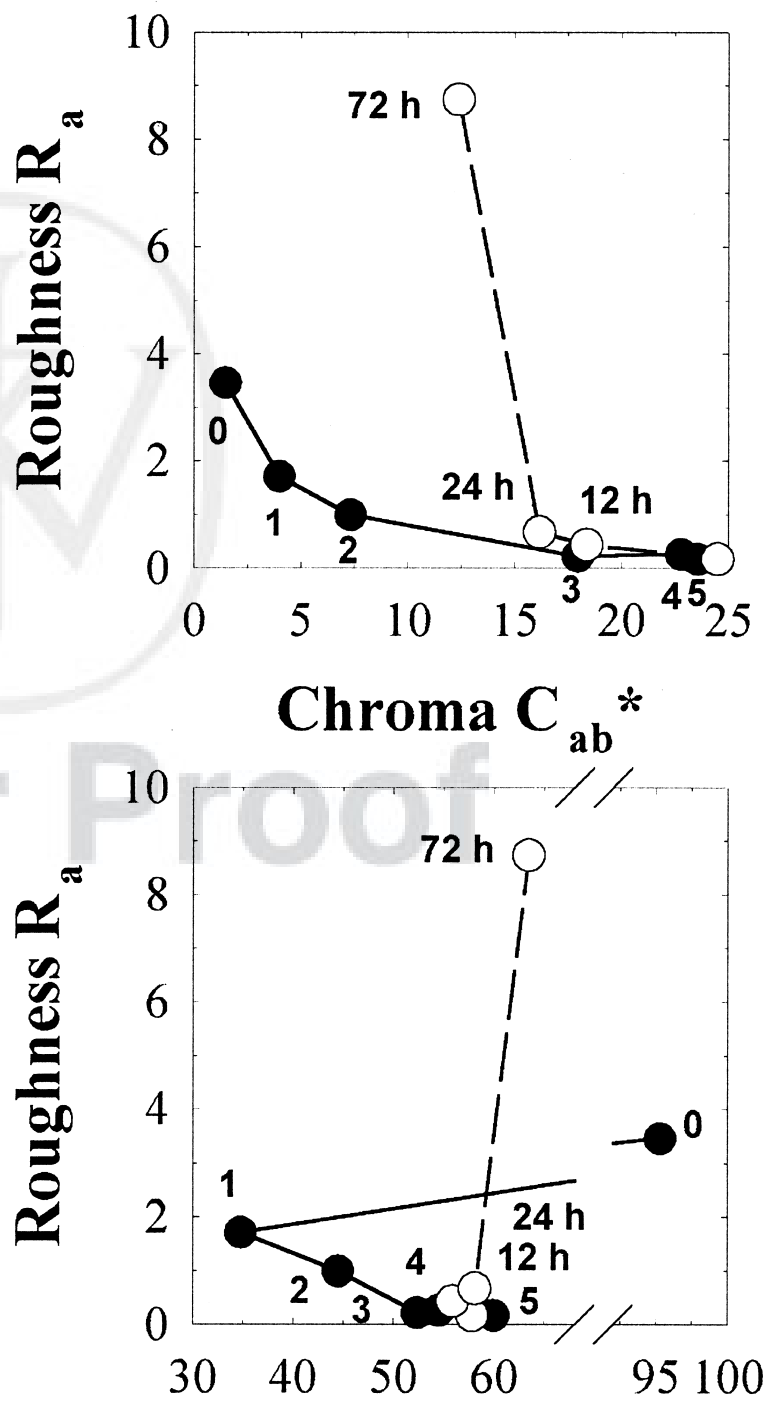

Hue angle $h_{a b} *$ (deg) 
TABLE V. Partial and total color differences between, on the one hand, the most polished and the sawn samples, and on the other, the sample exposed to the longest acid attack compared to the most polished sample.

\begin{tabular}{|c|c|c|c|c|c|c|c|c|c|c|}
\hline & \multicolumn{2}{|c|}{$\begin{array}{c}\text { Red } \\
\text { Alicante-1 }\end{array}$} & \multicolumn{2}{|c|}{$\begin{array}{c}\text { Red } \\
\text { Alicante-2 }\end{array}$} & \multicolumn{2}{|c|}{$\begin{array}{c}\text { Black } \\
\text { Marquina }\end{array}$} & \multicolumn{2}{|c|}{$\begin{array}{l}\text { White } \\
\text { Macael }\end{array}$} & \multicolumn{2}{|c|}{$\begin{array}{l}\text { Yellow } \\
\text { Triana }\end{array}$} \\
\hline & Polishing & $\begin{array}{c}\text { Acid } \\
\text { Attack }\end{array}$ & Polishing & $\begin{array}{c}\text { Acid } \\
\text { Attack }\end{array}$ & Polishing & $\begin{array}{c}\text { Acid } \\
\text { Attack }\end{array}$ & Polishing & $\begin{array}{c}\text { Acid } \\
\text { Attack }\end{array}$ & Polishing & $\begin{array}{l}\text { Acid } \\
\text { Attack }\end{array}$ \\
\hline$\Delta L^{*}$ & -21.55 & 13.03 & -20.7 & +5.1 & -36.79 & 16.23 & -0.98 & 1.71 & -2.22 & -0.48 \\
\hline$\Delta C^{*}$ & 22.09 & -12.11 & +25.3 & -10.1 & -4.63 & 1.91 & 0.30 & -0.52 & 4.94 & -3.42 \\
\hline$\Delta H^{\star}$ & -3.58 & +1.71 & -0.5 & -1.8 & -0.10 & -0.08 & 0.65 & 0.13 & 0.68 & -0.14 \\
\hline$\Delta E_{94}$ & 23.32 & 17.87 & 21.01 & 5.2 & 36.86 & 16.27 & 1.02 & 1.71 & 2.24 & 0.50 \\
\hline
\end{tabular}

Therefore, the longer the exposure time, the higher the roughness values (Fig. 3).

In addition to the inverse relationship between changes in roughness in both processes, it is worth noting that the mechanisms of roughness variation are completely different. The polishing process is homogeneous over the stone surface, which diminishes roughness mechanically. However, the chemical dissolution of grains produced by acid attack increases the surface roughness and depends greatly on heterogeneous petrographic features. This result may be attributed to grain distribution over the stone and grain size itself. In general, more pronounced changes in the roughness are also observed in the polishing process.

\section{Color Changes}

Color changes as a result of both polishing and acid attack are noticeable at first glance. To study the influence of roughness on color changes, chromatic parameters versus $R_{a}$ in both processes are plotted for Red Alicante-1 (Fig. 4).

During the polishing process, roughness, measured by $R_{a}$, decreases in the studied samples (Table IV). During this process, lightness $\left(L^{*}\right)$ decreases, whereas chroma $\left(C^{*}\right)$ increases. However, in spite of the significant hue angle changes, $\Delta h^{*}$ in Fig. 4, there are barely perceived hue differences, $\Delta H^{*}$ (Table V).

These changes in color of the Red Alicante- 1 can be seen in Fig. 5 in $b^{*}$ versus $a^{*}$ and $L^{*}$ versus $C^{*}$ diagrams. It can be clearly seen how the hue angle changes slightly throughout the polishing process. If the general limit of perceptibility is taken as 3 units in CIELAB space, ${ }^{7,8}$ it can be seen in Table $\mathrm{V}$ that the partial differences of the lightness $\Delta L^{*}$ and chroma $\Delta C^{*}$ greatly surpass the visual threshold in the two types of Red Alicante and Black Marquina, which show medium/low lightness (Table II). On the other hand, the partial difference of hue $\Delta H^{*}$ is below this visual limit in the majority of the stone samples. Therefore, the total color difference ${ }^{7,8} \Delta E_{94}$ in the two red stones and the black stone is due only to lightness and chroma changes, not to hue changes, as it may appear at first glance. This is clearly seen in Fig. 6, with the use of the same vertical numeric scale for the lightness, chroma, and hue differences. However, the total color difference $\Delta E_{94}$ in the lightest stones (White Macael and Yellow Triana) is below the perceptibility limit.

This result is extremely important, because there are no
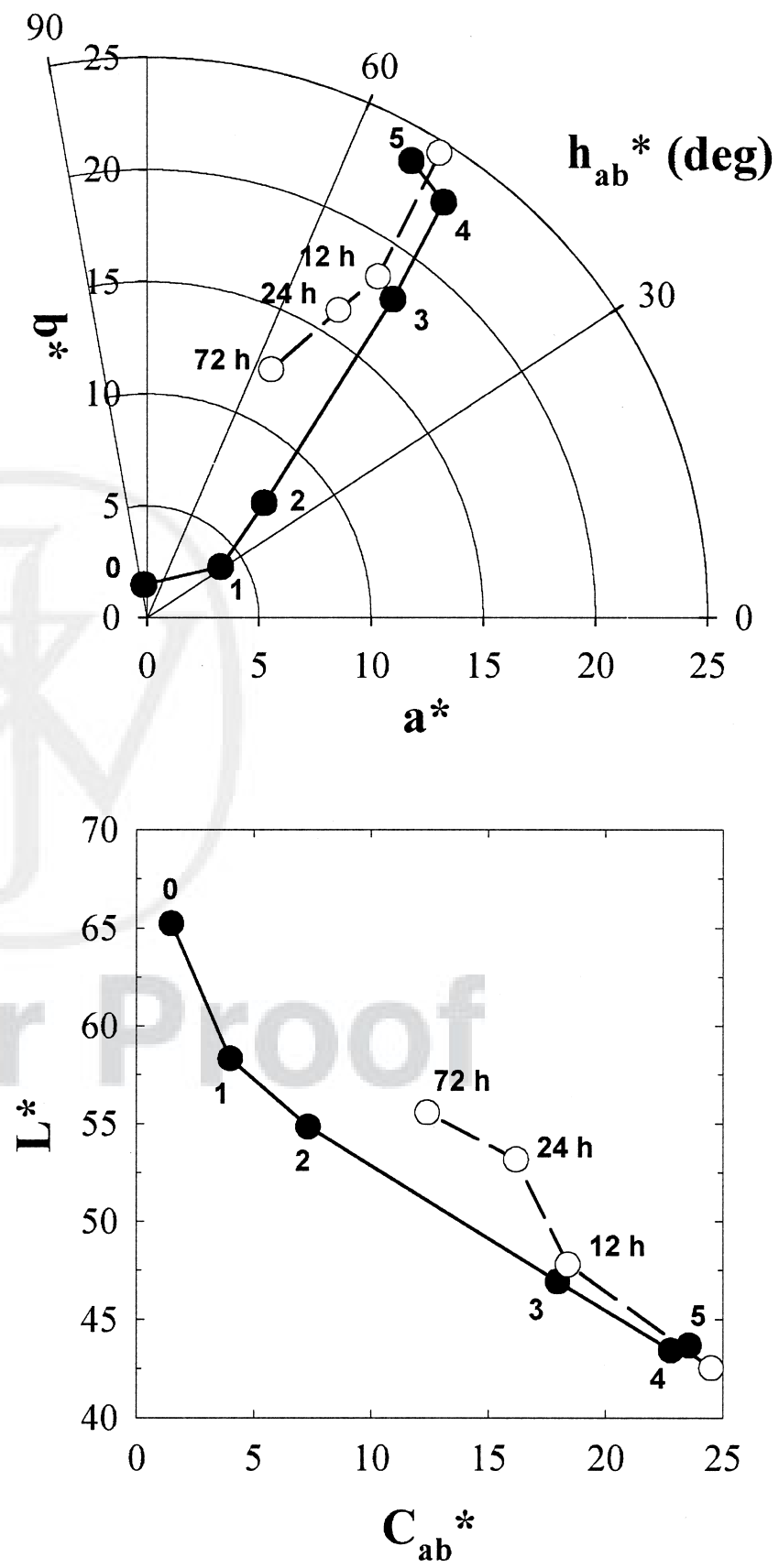

FIG. 5. Color changes of the Red Alicante-1 throughout the polishing $(\bullet)$ and acid attack $(\bigcirc)$ process in the $b^{*}$ versus $a^{*}$ (top) and $L^{*}$ versus $C^{*}$ (bottom) diagrams. Each symbol is also identified by a sublegend showing the partial characteristics of the two processes. 

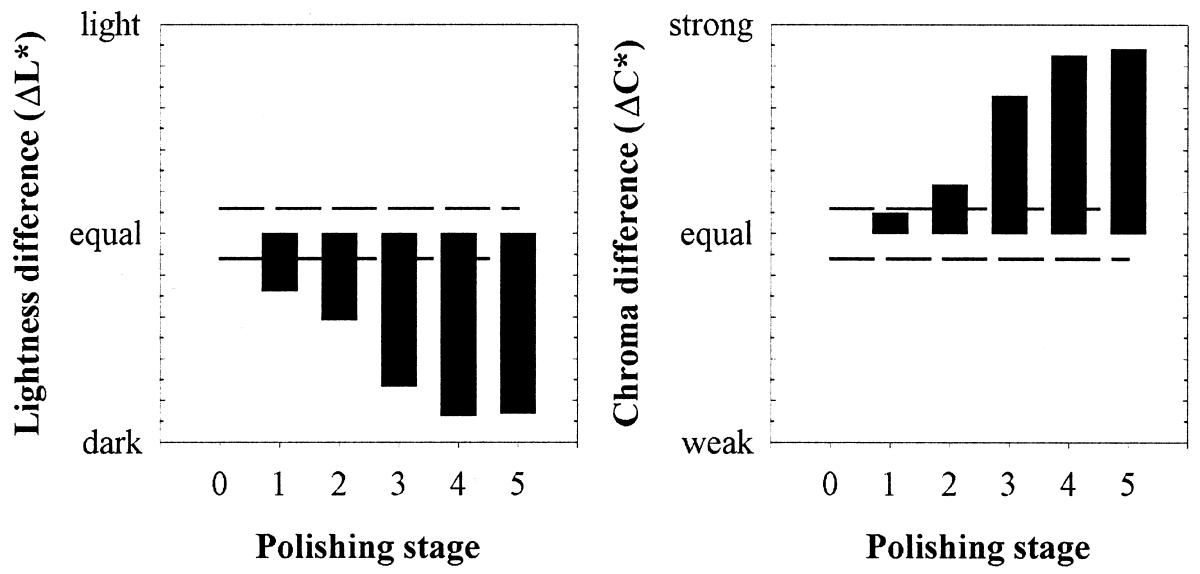

FIG. 6. Partial and total color differences of the Red Alicante-1 throughout the polishing process. The color reference is the sawn sample, without polish. The vertical numeric scales are the same, $[-25,+25]$ units, in the partial color differences $\Delta L^{*}, \Delta C^{*}$, and $\Delta H^{*}$ to show the relative weight of three chromatic variables on the total color difference $\Delta E_{94}$. The short dashed line indicates the perceptibility limit, which is equal to 3 units.
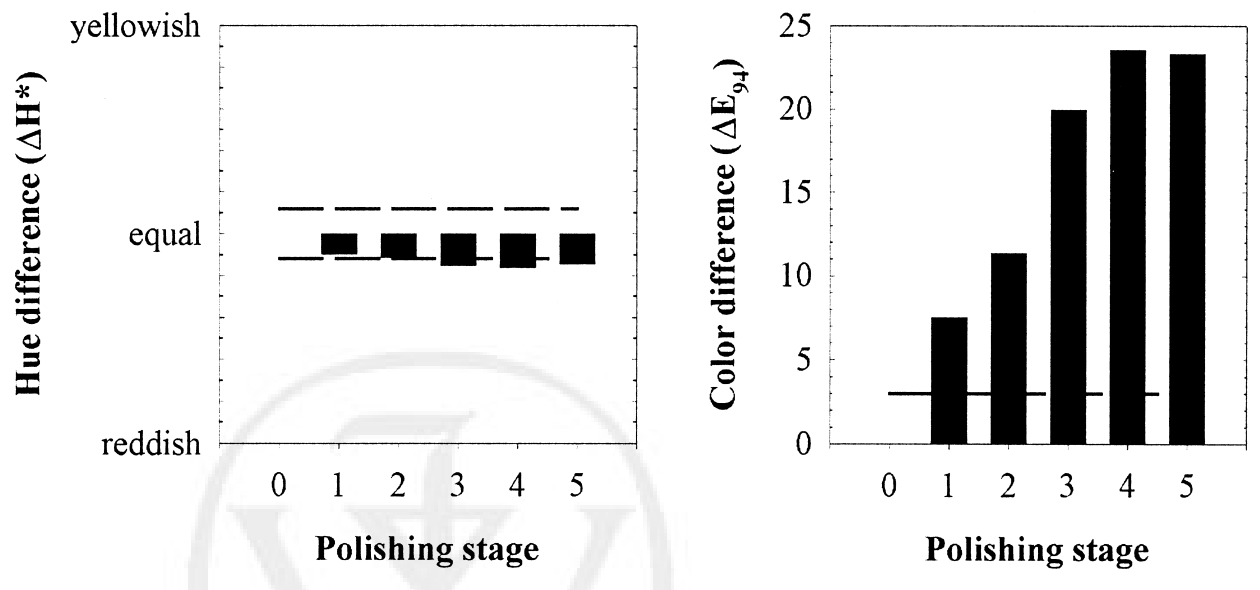

chemical reactions of the chromogen mineral in the polishing process. Therefore, the color change observed in this process can be attributed to the roughness of the stone surface. In the polishing experiment, the color evolution of Red Alicante-1, Red Alicante-2, and Black Marquina is higher than that in White Macael and Yellow Triana (Table V).

The changes in color and, therefore, in aesthetic characteristics during polishing show how important it is to optimize this process, because it is the most common finish used for this kind of building stones.

On the other hand, the acid attack on the materials studied produces an inverse color change. Thus, during the acid attack, the grains dissolve; therefore, surface roughness increases. During the decay process, the lightness increases, whereas the chroma decreases. However, there are no significant variations in the hue (Table $\mathrm{V})$.

This color change for the Red Alicante- 1 can also be seen in Fig. 5 in $b^{*}$ versus $a^{*}$ and $L^{*}$ versus $C^{*}$ diagrams. It can be seen clearly how the hue angle changes slightly throughout the acid attack course. Taking into account the same perceptibility limit as above, it can be seen in Table $\mathrm{V}$ that the partial differences of the lightness $\Delta L^{*}$ and chroma $\Delta C^{*}$ again greatly surpass the visual threshold in the two types of Red Alicante and Black Marquina that show medium/low lightness (Table II). On the other hand, the partial difference of hue, $\Delta H^{*}$, is below this visual limit in the majority of the stone samples. This is clearly seen in Fig. 7, with the use of the same vertical numeric scale for the lightness, chroma, and hue differences. However, the total color difference $\Delta E_{94}$ in the lightest stones (White Macael and Yellow Triana) is again below the perceptibility limit.

Therefore, as occurs in the study on polishing, there is no change in the chromogen mineral during the acid attack.

During polishing stages 1-3 (grinding), the color changes notably, whereas in the final stages 4 and 5 (diminishing microroughness), the color is stabilized and reaches its natural color. Therefore, changes in color are closely linked to stone surface roughness.

On the other hand, during the acid attack, the stone grains are dissolved. In the first steps, the solution is more undersaturated than that for a long time of exposure. Therefore, we can conclude that the dissolution process is more aggressive at the beginning of the experiment. This result proves once more that the color of the stone depends greatly on stone surface roughness.

The results for changes in color of different stones are summarized in Table V. Dark or high-chroma stones (Red Alicante-1, Red Alicante-2, and Black Marquina) are particularly affected in both the polishing and acid attack processes, whereas in high-lightness stones (White Macael and Yellow Triana), there is no important change in color 

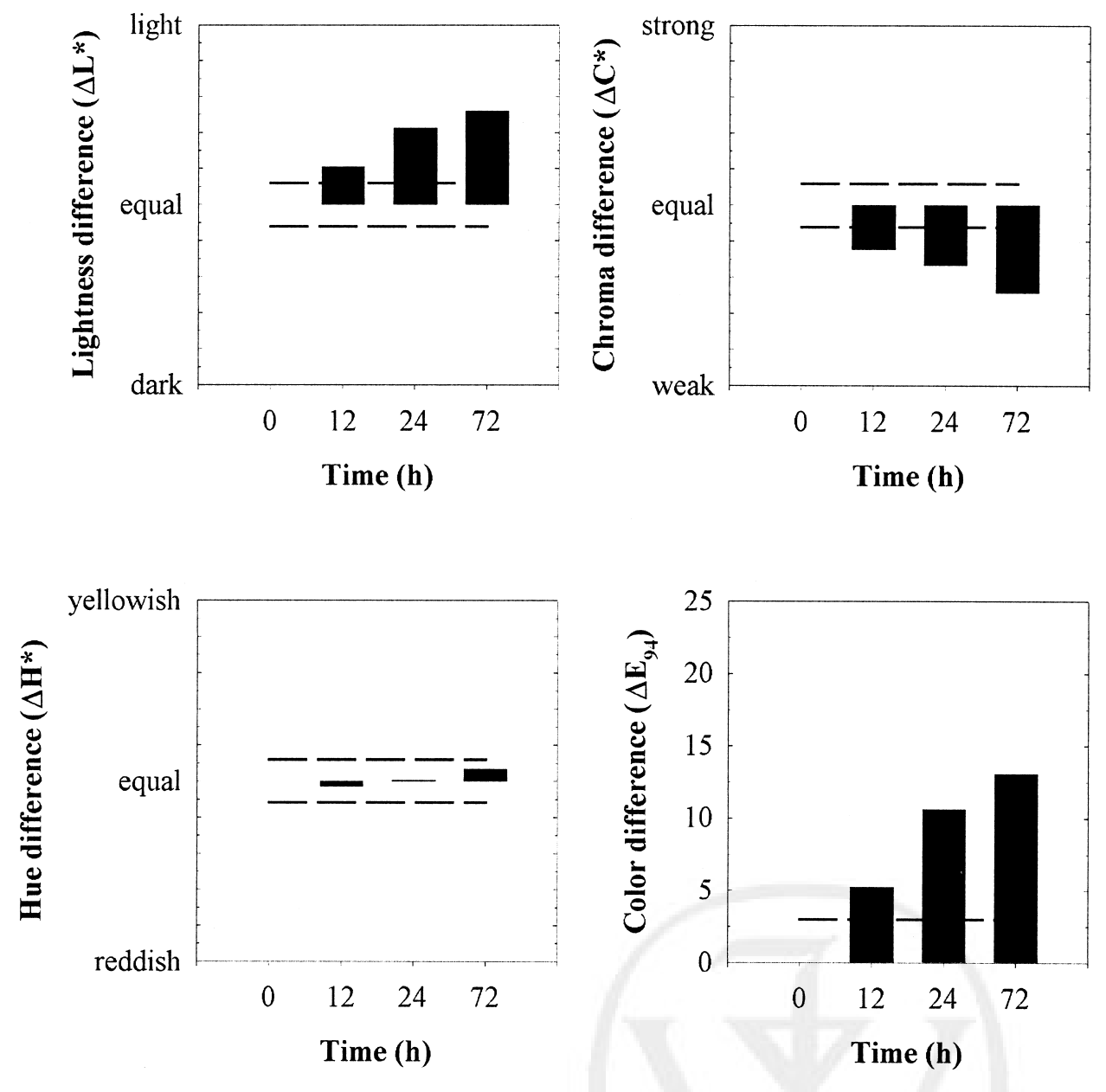

FIG. 7. Partial and total color differences of the Red Alicante-1 during the acid attack course, taking the maximum polished sample as the color reference. The vertical numeric scales are the same, [-25, $+25]$ units, in the partial color differences $\Delta L^{*}, \Delta C^{*}$, and $\Delta H^{*}$ to show the relative weight of three chromatic variables on the total color difference $\Delta E_{94}$. The short dashed line indicates the perceptibility limit, which is equal to 3 units.

during these processes. Also, the partial color differences $\Delta L^{*}$ and $\Delta C^{*}$, and total color difference $\Delta E_{94}$ in the polishing process are higher than those in the acid attack. Although surface roughness changes in all stones, only chromatic variations are produced in high-chroma stones. Therefore, this kind of building material is more susceptible to aesthetic decay caused by weathering action.

The most important visual effect on the stones we studied is produced by lightness and chroma. Moreover, both variables greatly influence the total color difference $\left(\Delta E_{94}\right)$. From a perceptual point of view, the hue does not contribute to aesthetic changes; nevertheless it gives us an indirect result: The chromogen mineral does not change during surface decay.

This result questions the widely used hypothesis that changes in the color of stone are only produced by changes in chromogen minerals. Moreover, the chromogen in Red Alicante-1, Red Alicante-2, and Yellow Triana are oxidized minerals that hardly vary at all when exposed to oxidizing environments such as the atmosphere or acid solution. Furthermore, chromogen minerals in Black Marquina are completely different than those in the other samples and change color significantly. This change can be explained by the increase in surface roughness rather than a change in the oxidation state of chromophores. Therefore, specific char-

acterization of each stone is required to understand and predict color changes that result from weathering.

An increase in surface roughness is one of the most important aesthetic decay mechanisms that this kind of material can undergo through weathering action. However, it is sometimes necessary to take into account that because of environmental conditions and urban pollution, color changes depend not only on surface roughness but also on the particle and precipitated mineral colors deposited over on the stone surface.

\section{CONCLUSIONS}

From the results presented and discussed above, we have demonstrated that the color variations caused by acid attack depend basically on the surface roughness variations and the type of building stones. Thus, first, in Red Alicante stones with a medium or high chroma, the lightness $L^{*}$ increases and the chroma $C^{*}$ decreases when surface roughness is increased during the different acid attack stages. Second, in Black Marquina with both low chroma and lightness, only the lightness increases. Finally, in White Macael and Yellow Triana marbles with low chroma and high lightness, the lightness and chroma changes are almost imperceptible. However, no hue change occurs in any of the analyzed 
stones; therefore, this factor does not contribute to color changes.

The lack of hue variation proves that color change is due mainly to alterations in surface roughness and not to chemical reactions that may alter the oxidation state of the chromophore in the chromogen of the stone. This final analysis is corroborated colorimetrically, because the surface roughness and change in color during the polishing process has precisely the opposite effect to that of the acid attack process on each of the stones.

The polishing process effects a mechanical decrease in the surface roughness, and its detailed study in this article has been extremely useful not only for understanding the color change mechanism but also for optimizing the process, because these stones represent the most common finish

\section{ACKNOWLEDGMENT}

Our thanks to M. Palomo (University of Alicante) for his invaluable help in the polishing process, and to M. Naylor (International Relations Centre, UA) for the English revision of the article.

1. García-Talegon J, Vicente MA, Vicente-Tavera S, Molina-Ballesteros E. Assessment of chromatic changes due to artificial ageing and/or conservation treatments of sandstones. Color Res Appl 1998;23:4651.

2. Iñigo AC, Vicente-Tavera S, Rives V, Vicente MA. Color changes in the surface of granitic materials by consolidated and/or water repellent treatments. Color Res Appl 1997;22:133-141.

3. Fort R, Mingarro F, López de Azcona MC, Rodrigez Blanco J. Chromatic parameters as performance indicators for stone cleaning techniques. Col Res Appl 2000;25:442-446.

4. García Pascual N, Sánchez de Rojas MI, Frias M. Measurement of color in different construction materials: The restoration in sandstone buildings. Mater Construcc 1999;49:29-45.

5. Winkler EM. Stone in architecture: Properties, durability. Berlin: Springer-Verlag; 1997.

6. Simon S, Snethlage R. Marble weathering in Europe. Results of EUROCARE-EUROMARBLE Exposure Programme 1992-1994. In: Riederer J. editor. Proceedings of the 8th International Congress on Deterioration and Conservation of Stone. Berlin; 1996. p 159-166.

7. Berns RS. Billmeyer and Saltzman's principles of color technology. New York: John Wiley \& Sons; 2000.

8. Völz HG. Industrial color testing. Weinheim: Wiley-VCH; 2001.

9. Wyszecki G, Stiles WS. Color science: Concepts and methods, quantitative data and formulae. 2nd edition. New York: John Wiley \& Sons; 1982.

10. Dalal EN, Natale-Hoffman KM. The effect of gloss on color. Color Res Appl 1999;24:369-376.

11. Tilley R. Colour and optical properties of materials. Chichester, UK: John Wiley \& Sons; 2000.

12. Nassau K. The physics and chemistry of color. 2nd edition. New York: John Wiley \& Sons; 2001.

13. Erdogan M. Measurement of polished rock surface brightness by image analysis method. Eng Geol 2000;57:65-72.

14. Hunt RWG. Measuring colour. Chichester, UK: Ellis Horwood; 1987.

15. Folk R. Spectral subdivision of limestone types. In: Ham WE, editor. AAPG Bulletin, Mem.1. Tulsa, OK; 1962. p 62-84.

16. Benavente D, Bernabéu A, Fort R, García del Cura MA, La Iglesia A, Ordóñez S. Caracterización mineralógica, petrológica y petrofísica del mármol comercial Rojo Alicante (Cavarrasa, Alicante). Geotemas 2000;1:255-260.

17. Xeidakis GS, Samaras IS. Durability of sandstone used as a principal building and decorative material in ancient Addera, Xanthi, N. Greece. Bull Int Assoc Eng Geol 1996;54:137-147.

18. Johnson JB, Haneef SJ, Hepburn BJ, Hutchinson AJ, Thompson GE, Wood GC. Laboratory exposure system to simulate atmospheric degradation of building stone under dry and wet deposition conditions. Atmos Environ 1990;24:2585-25921. 